\title{
The influence of flow and season upon leaf-litter breakdown in monsoonal Hong Kong streams
}

\author{
Sophia Q. Niu • David Dudgeon
}

Received: 7 July 2010/Revised: 12 November 2010/Accepted: 5 December 2010/Published online: 17 December 2010

(C) The Author(s) 2010. This article is published with open access at Springerlink.com

\begin{abstract}
We investigated the effects of water extraction and flow regime on leaf litter breakdown in 10 Hong Kong streams experiencing varying degrees of extraction: five with severe extraction ( $>85 \%$ downstream flow removed), four with moderate extraction (20-85\% removed), and one without extraction $(\sim 0 \%$ removed). Breakdown rates, macroinvertebrate assemblages and nutrients were compared in upstream (reference) reaches and downstream reaches with reduced flow in each stream during highflow (wet season) and low-flow (dry season) conditions to determine whether responses to flow were influenced by Hong Kong's monsoonal climate. Litter breakdown was slower in downstream reaches during the wet season, and discharge was the main determinant of breakdown rate in both reaches across the 10 study streams. In contrast, inter-reach differences in breakdown during the dry season were small and unrelated to flow. Instead, breakdown rates among streams were influenced by the abundance of
\end{abstract}

Handling editor: Nicholas R. Bond

Electronic supplementary material The online version of this article (doi:10.1007/s10750-010-0573-4) contains supplementary material, which is available to authorized users.

S. Q. Niu · D. Dudgeon ( $\varangle)$

School of Biological Sciences, The University of Hong

Kong, Pok Fu Lam Road, Hong Kong S.A.R., China

e-mail: ddudgeon@hkucc.hku.hk detritivorous shredders and chironomids (Chironominae), as well as phosphate concentrations, indicating the importance of biological processing of litter under low-flow conditions. Although litter breakdown rates appear to offer a promising functional indicator of flow-reduction impacts during the wet season, the pattern seen reflected the physical effects of flow rather than any underlying biological processes, and the lack of response to flow reduction during the dry season was notable.

Keywords Ecosystem function - Water extraction · Discharge $\cdot$ Shredders $\cdot$ Liquidambar $\cdot$ Brotia

\section{Introduction}

Flow alteration is one of the major anthropogenic threats to freshwater biodiversity and ecosystem functioning, and considerable research has been devoted to managing the conflicting interests of multiple users of water and the need to protect lotic ecosystems (e.g. Dudgeon et al., 2006; Arthington et al., 2010). Reductions in flow volume and elimination of natural flow variability have various impacts including reduced habitat availability and heterogeneity, reductions in species richness and shifts in composition of macroinvertebrates and fish communities and a higher risk of invasion by exotic species (Bunn \& Arthington, 2002). There is now a general consensus that knowledge of ecological 
responses to flow should be used to inform environmental flow (e-flow) allocations that mimic the natural pattern of flow variability in order to sustain biodiversity and the functional properties of streams and their adjacent floodplains (Poff et al., 2010; Richter, 2010). Development of such hydro-ecological relationships has frequently been based upon studies of changes in the community structure of macroinvertebrates and fishes (reviewed by Dewson et al., 2007; Poff \& Zimmerman, 2010), but structural attributes such as species composition and diversity should not be the sole criterion for evaluating stream integrity. They need to be supplemented by functional measures (Bunn \& Davies, 2000; Gessner \& Chauvet, 2002), since the manner and timing of structural and functional responses to anthropogenic disturbances can vary thereby yielding complementary information on impacts (Sandin \& Solimini, 2009). However, the response of these functional indictors to hydrological conditions must be demonstrated if they are to provide useful tools for flow management and restoration (Lancaster \& Downes, 2010).

Leaf litter breakdown is a well-studied process that has been used as a functional measure of stream condition (Gessner \& Chauvet, 2002; Death et al., 2009; Sandin \& Solimini, 2009). It is influenced by a variety of physical (e.g. fragmentation and abrasion by current) and biological processes (microbial decomposition and macroinvertebrate consumption), and has been used to assess the ecological consequence of such factors as land use and riparian condition (Bird \& Kaushik, 1992; Hagen et al., 2006; McKie \& Malmqvist, 2009) as well as, less frequently, channelization and flow regulation (Woodcock \& Huryn, 2005; Paul et al., 2006; Death et al., 2009). Litter breakdown process is also influenced by hydrological regime, especially current velocity and high-flow events (Bird \& Kaushik, 1992; Lepori et al., 2005; Paul et al., 2006). While stream flow alone plays a minor role in determining breakdown directly, its effect seems more usually indirect by way of an influence on biological processes (Woodcock \& Huryn, 2005; Ferreira et al., 2006; Hoover et al., 2006). For instance, breakdown rates of two leaf species in an Arizona stream decreased by $\sim 20 \%$ when flows were reduced by $95 \%$, and this decrease was associated with cooler temperatures as well as lower fungal biomass and macroinvertebrate diversity on the leaves (Muehlbauer et al., 2009). In other cases, flow reductions can accelerate litter breakdown as a result of increased nutrient loads that enhance fungal colonization (Short \& Ward, 1980).

Streams in monsoonal Hong Kong are subject to aggressive water extraction for municipal water supplies, leading to reductions in diversity of benthic macroinvertebrates and impaired periphyton condition (Dudgeon, 1992; Niu \& Dudgeon, 2011). E-flow allocations should involve functional parameters to limit such impacts, and need to be adjusted seasonally, to take account of much lower flows (and hence greater scope for impairment) during the dry season (Niu \& Dudgeon, 2011). We investigated the effects of water extraction and flow regime on litter breakdown in 10 Hong Kong streams experiencing varying degrees of water extraction from downstream reaches. By comparing litter breakdown rate in upand downstream reaches of each stream during both high-flow (wet season) and low-flow (dry season) conditions, we attempted to test the hypotheses that (1) breakdown rate would differ between up- and downstream reaches in response to flow reduction, (2) the response would vary among streams with different degrees of flow reduction and (3) the response would be influenced by seasonal changes in flow associated with the monsoonal climate. Macroinvertebrate assemblages and nutrients were also monitored so that their response to changed flows, and any consequential influence on litter breakdown, could be determined. Data gathered was also used to compare the performance and sensitivity of leaf litter breakdown-a functional indicator of stream condition-with changes in macroinvertebrate assemblage structure.

\section{Methods}

Study sites

Hong Kong (lat. $22^{\circ} 08^{\prime}-23^{\circ} 35^{\prime} \mathrm{N}$ ) has a tropical monsoonal climate with two distinct seasons: the wet season (April-September) associated with the southwest monsoon, when $\sim 80 \%$ of the annual rainfall occurs, and the dry season (October-March) when the northeast monsoon prevails (Dudgeon \& Corlett, 2004). Stream hydrology is characterised by a high degree of flow variability with intense spates and 
highly 'pulsed' flows during the wet season (Dudgeon $\&$ Corlett, 2004). This study included 10 second- to fourth-order unpolluted perennial streams (wetted width $=2-6 \mathrm{~m}$ during base flows), three on Lantau Island and seven in the mainland New Territories (S1-S10: Fig. 1). All had stony beds and drained hilly (76-213 m elevation) shrubland or secondary forest within or adjacent to protected areas (Country Parks). The streams experienced varying degrees of water extraction, due to the presence of small dams connected to a network of channels and tunnels that capture water for Hong Kong's municipal supply (Dudgeon, 1996).

Field and laboratory procedures

Two matched reaches between 100 and $200 \mathrm{~m}$ apart with comparable physical conditions were selected along each stream: one above (upstream) and one below (downstream) of a water extraction point. Thus, the downstream reaches received reduced flow, while the upstream reach served as a reference site. Measurements of flow and litter breakdown rates were made and benthic macroinvertebrates were sampled in both reaches on eight occasions: three occasions at approximately monthly intervals between June and September 2007 (the wet season), three occasions between December 2007 and March 2008 (the dry season), and two between July and August 2008 (the second wet season). Due to anthropogenic disturbance of downstream reaches of two streams (S5 and S7), work was abandoned during the dry season and the second wet season in S7, and during the second wet season in S5; S7 was substituted by S10 which had similar characteristics and was sampled thrice during both seasons (for details, see Niu \& Dudgeon, 2011). Overall, therefore, 10 streams were sampled during one or both wet seasons (seven streams with five temporal replicates, and three with three replicates; $n=44$ ) and nine streams were sampled during the dry season (three temporal replicates each; $n=27$ ).

In-stream flow parameters were measured at three representative cross-sections at least $15 \mathrm{~m}$ apart along each study reach during every visit. They were wetted width, water depth at 50-cm intervals, and current velocity at $10-\mathrm{cm}$ intervals (at $40 \%$ of water-column depth) which was measured with a Swoffer Model 2100 current meter (Swoffer Instruments Inc., Seattle, Washington, US). From these data, discharge (i.e. volume of flow moving past a given cross-section per second: $Q, 1 \mathrm{~s}^{-1}$ ) was estimated using the velocitywetted-area method (Gordon et al., 2004). Widthspecific discharge $\left(Q_{\mathrm{w}}\right)$ was also estimated, where $Q_{\mathrm{w}}$ equalled the ratio of mean discharge over mean width among the three cross-sections. Flow alteration due to water extraction was quantified by the $\%$ reduction in
Fig. 1 A map of Hong Kong showing the locations of the 10 study streams. The lines indicate the major water tunnel networks that divert stream water to reservoirs. S1 Ha Fa Shan, S2 Pak Sha O, S3 Hau Tong Kai, S4 Tai Shui Hang, S5 Tung Chung, S6 Tai Lam Wu, S7 Wong Lung Hang, S8 Tai Po Kau, S9 Mui Tze Lam, S10 Shek Mun Kap

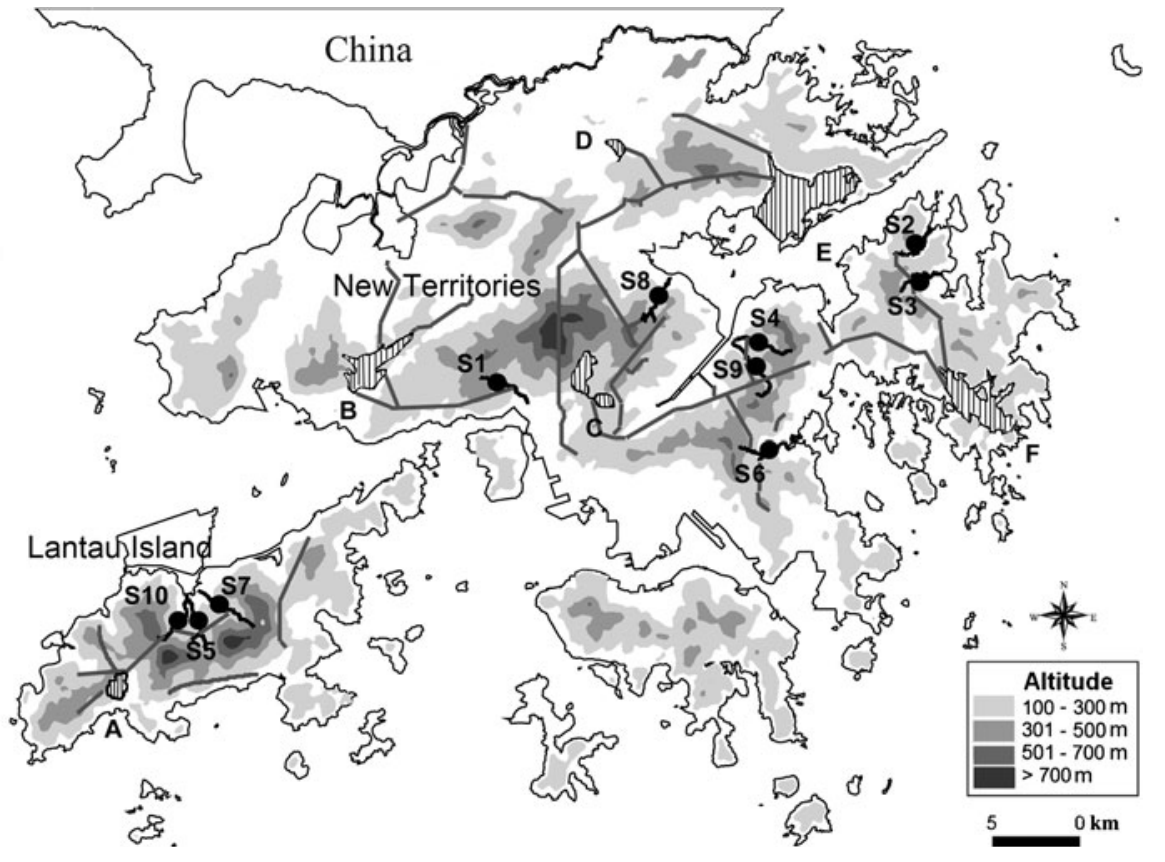


$Q$ and $Q_{\mathrm{w}}$ from up- to downstream (i.e. $\Delta Q$ and $\Delta Q_{\mathrm{w}}$ ) on each sampling date. Mean $\Delta Q$ and $\Delta Q_{\mathrm{w}}$ among sampling dates were used to indicate the extent of hydrological alteration for each stream in each season. An initial test indicated that there was no difference in $\Delta Q$ between the two wet seasons (Niu \& Dudgeon, 2011) and thus data from both years have been combined.

Water samples for nutrient analysis (nitrate, nitrite, ammonia combined as total inorganic nitrogen [total $\mathrm{N}]$; total phosphate $\left[\mathrm{PO}_{4}\right]$ ) were collected from both reaches of each study stream once in the second wet season and dry season, and their concentrations measured with a flow injection analyser (QuikChem 8000, Lachat Instruments, Inc., Milwaukee, Wisconsin, USA) based on automated phenate methods for ammoniacal nitrogen and colorimetric methods for nitrate, nitrite, and total $\mathrm{PO}_{4}$ (APHA, 1995). Water temperatures in each reach were recorded with maximum-minimum thermometers and Maxim iButtons ${ }^{\circledR}$ (Maxim Integrated Products, Inc., Sunnyvale, CA, US).

Litter breakdown rates were quantified using Liquidambar formosana Hance (Hamamelidaceae) as a model species. L. formosana is a common deciduous tree native to Hong Kong, which has been widely planted. The nitrogen content of abscised leaves is $\sim 1.2 \%$ of dry mass, and the carbon to nitrogen ratio is $\sim 37$ (Li et al., 2009). Breakdown of $L$. formosana is generally fast in Hong Kong streams (Li \& Dudgeon, 2009; Li et al., 2009), and thus a 28-day in-stream exposure period was sufficient to test for possible differences in breakdown rates between upstream (reference) and downstream (experiencing reduced flow) reaches. Abscised leaves were collected in April 2007 and March 2008 and air-dried to constant mass. Ten litter bags (4-mm mesh) containing $4.0 \pm 0.1 \mathrm{~g}$ of air-dried leaves were placed in runs in each stream on eight occasions (three in the dry season, five in the wet season). Five bags were assigned randomly to each reach and positioned on the streambed. The mesh size used allows entry of most of the litter-associated detritivores, including shredding caddisflies and atyid shrimps, although it may exclude larger-sized Brotia hainanensis snails (Prosobranchia: Pachychilidae). The bags were retrieved after 28 days by enclosing them in a $300-\mu \mathrm{m}$ mesh net prior to removal from the stream, then placed in individual plastic bags and transported in a cool box to the laboratory where they were stored at $-20^{\circ} \mathrm{C}$. Subsequently, leaves from each litter bag were rinsed gently with tap water, oven-dried at $60^{\circ} \mathrm{C}$ for $72 \mathrm{~h}$ to yield dry mass, then ashed at $500^{\circ} \mathrm{C}$ in a muffle furnace for $4 \mathrm{~h}$ and reweighed to calculate ash-free dry mass (AFDM). In addition, five bags of air-dried leaves were oven dried, weighed, ashed, and reweighed to calculate a conversion factor from initial air-dry mass to AFDM. Breakdown rates in each reach were expressed as mean \% leaf mass loss (\% LML) from the five litter bag samples over each 28-day period.

Benthic macroinvertebrates were collected from a 10-rock stratified sample from each study reach on each stream visit using a $300-\mu \mathrm{m}$ mesh net (see Niu \& Dudgeon, 2011 for details). At each up- or downstream reach, cobbles of 15-20 cm maximum diameter $\left(\sim 400 \mathrm{~cm}^{2}\right.$ surface area) were collected from riffle-pool sequences in a stratified manner (equal numbers of cobbles were collected from riffles and pools). Macroinvertebrates were removed from stones and preserved in $70 \%$ ethanol. They were handpicked from each sample in the laboratory under a stereomicroscope, identified to species, genus, subfamily (Diptera: Chironomidae) or family (other Diptera), and counted to yield abundance per 10-rock sample. Functional feeding group (FFG) composition was also investigated, with assignments following $\mathrm{Li}$ \& Dudgeon (2008), so that the abundance of detritivorous shredders could be estimated.

Statistical analyses

Three-way repeated-measures ANOVA (Zar, 1999) was conducted to compare \% LML between up- and downstream reaches during the wet and dry seasons. The analyses incorporated reaches (up- vs. downstream) and seasons (wet vs. dry) as within-subject factors and streams as the subject, with sampling dates in each season treated as replications. When significant season $\times$ reach interactions were detected, two-way analyses within each season were conducted using reaches as the within-subject factor and streams as the subject. Stream nutrient concentrations, which were measured once only per season, were analysed by repeated-measures ANOVA without replication, and thus the reach $\times$ season $\times$ stream interaction was not included in the model.

Where ANOVA revealed significant betweenreach differences in litter breakdown rate, the 
magnitude of the between-reach differences ( $\Delta \mathrm{LML}$ ) were calculated by simple subtraction. Relationships between the degree of hydrological alteration (i.e. $\Delta Q$ and $\Delta Q_{\mathrm{w}}$ ) versus $\Delta \mathrm{LML}$ were examined using bivariate linear regressions with replications (Zar, 1999). The mean $\Delta Q$ and $\Delta Q_{\mathrm{w}}$ of each stream within each season were used as independent variables, each corresponding to replicated measurements of $\triangle \mathrm{LML}$ (i.e. on three or five sampling dates depending on season), with separate regression analyses conducted for the wet $(n=44)$ and dry $(n=27)$ seasons. In addition, bivariate linear regression analyses were undertaken to examine potential relationships between absolute discharge parameters $\left(Q\right.$ and $\left.Q_{\mathrm{w}}\right)$ versus \% LML, with separate analyses for up- and down-stream reaches during each season (thus wet $n=44$, dry $n=27$ ). A conservative significance level $(\alpha=0.01)$ was selected for these regressions. ANOVA and bivariate linear regressions were carried out with SPSS 15.0 (SPSS Inc., Chicago, IL, USA). All percentage data were arcsine-square root transformed, and $\log _{10^{-}}$or square-root transformations were applied where they improved the normality or explanatory power of regressions.

Hierarchical partitioning analyses were conducted in order to identify the relative importance of environmental factors that may regulate litter breakdown rate during the wet and dry seasons. Hierarchical partitioning compares goodness-of-fit of all possible models in a multiple regression setting, and estimates the independent effects of each predictor, so that the most likely causal factors can be identified even in instances where there is multicolinearity among potential predictors (for details, see Chevan \& Sutherland, 1991; Mac Nally, 2000). Data on nutrients and stream discharge as well as benthic macroinvertebrate attributes (see below) were included as predictors in the analyses. Separate analyses were conducted for each season.

We considered the following macroinvertebrate attributes as potential predictors: total taxon richness (TTrich), abundance of Chironominae (Chironomidae), abundance of all shredders, and abundance of the facultative shredder B. hainanensis. The abundance of Chironominae was included as they are the most numerous litter-associated macroinvertebrates in Hong Kong streams (Dudgeon \& Wu, 1999; Li et al., 2009). Discharge $Q$, width-specific discharge
$Q_{\mathrm{w}}$, and current velocity were correlated with each other ( $r>0.8$ ), and thus only $Q$ was included in the analyses. Likewise, there was redundancy between shredders and B. hainanensis snails $(r=0.8)$, as the latter constituted $\sim 90 \%$ of shredder abundance; thus a separate analysis with shredders substituted by B. hainanensis was conducted. Up- and downstream reaches of nine streams (S7 was excluded since no nutrient data were collected during the wet season) were treated as replicates ( $n=18$ per season) in the analysis, which was conducted with $\mathrm{R}$ version 2.8 .1 (hier.part package; available online at http://cran.rproject.org/).

\section{Results}

Mean wet-season discharge ranged from 68-393 $1 \mathrm{~s} \mathrm{~s}^{-1}$ $\left(\right.$ mean $\left.=190 \mathrm{l} \mathrm{s}^{-1}\right)$ in upstream reaches and 3-137 $1 \mathrm{~s}^{-1}\left(\right.$ mean $\left.=461 \mathrm{~s}^{-1}\right)$ downstream across the 10 streams; discharge declined by 10-98\% (mean reduction $=69 \%$ ) due to water extraction. The equivalent values for dry-season discharge were $3-181 \mathrm{~s}^{-1}$ $\left(\right.$ mean $\left.=91 \mathrm{~s}^{-1}\right)$ upstream and 0.3-11 $1 \mathrm{~s}^{-1}$ (mean = $31 \mathrm{~s}^{-1}$ ) downstream, representing a reduction of 4-98\% (mean reduction $=58 \%$ ). S1 was bisected by a non-functioning catchwater channel and was not subject to any water extraction; hence, this stream was indicative of nil extraction conditions $(\Delta Q \sim 0 \%)$. Moderate flow reduction $(\Delta Q=20-85 \%)$ occurred in four streams (S2, S3, S4, and S5), while severe flow reduction $(\Delta Q \geq 85 \%)$ occurred in further five streams (S6, S7, S8, S9, and S10). Trends in flow reduction represented by $\Delta Q$ and $\Delta Q_{\mathrm{w}}$ were essentially the same (for details, see Niu \& Dudgeon, 2011), and thus only results for $\Delta Q$ have been presented here. Nutrient concentrations were generally lower during the wet season (total $\mathrm{N}$ : 6.5 vs. $52.7 \mu \mathrm{g} \mathrm{l}^{-1} ; \mathrm{PO}_{4}: 2.5$ vs. $3.3 \mu \mathrm{g} \mathrm{l}^{-1}$ ), although this seasonal variation was only significant for total $\mathrm{N}\left(F_{1,8}=8.63, P=0.019\right)$. There were no between-reach differences in total $\mathrm{N}$ $\left(F_{1,8}=1.27, \quad P>0.05\right) \quad$ or $\quad \mathrm{PO}_{4} \quad\left(F_{1,8}=0.57\right.$, $P>0.05)$ during either season, with $\mathrm{N}$ ranging from 2.4-32.6 versus 3.6-32.2 $\mu \mathrm{g} \mathrm{l}^{-1}$ in up- versus downstream reaches during the wet season and 11.3-186.1 $\mu \mathrm{g} \mathrm{l}^{-1}$ versus 3.2-100.8 $\mu \mathrm{g} \mathrm{l^{-1 }}$ during the dry season. The equivalent values for $\mathrm{PO}_{4}$ were 1.1-4.4 versus $1.2-4.4 \mu \mathrm{g}^{-1}$ (wet) and 1.6-4.8 versus $1.7-4.9 \mu \mathrm{g} \mathrm{l}^{-1}$ (dry). 
Litter bags from one set of samples in the upstream reaches in S1, S3, and S5 were lost during spates, and thus the sample size for the up- versus downstream comparison for the wet season was reduced from 44 to 41. Breakdown rates were significantly lower in downstream reaches (mean \% LML $\pm \mathrm{SE}=54.9 \pm$ 3.0 vs. $42.0 \pm 3.5 \%$ ) during the wet season, but were similar between reaches during the dry season $(19.1 \pm 1.0$ vs. $17.6 \pm 1.1 \%$ ) (Table 1; Fig. 2 ; for details, see Appendix in Supplementary material). Regardless of the between-reach differences, breakdown rates were greater during the wet season than the dry season (48 vs. 18\% LML; Table 1; Fig. 2). The faster litter breakdown may be partially attributable to higher discharge (range $=3-303$ vs. $0.3-181 \mathrm{~s}^{-1}$ ) and water temperatures $\left(\right.$ mean $=24.0$ vs. $16.4^{\circ} \mathrm{C}$ ) during the wet season, although the greater flow volume apparently diluted total $\mathrm{N}$ (mean $=6.5$ vs. $52.7 \mu \mathrm{g} \mathrm{l}^{-1}$ ).

Although litter breakdown rates were more rapid in upstream reaches during the wet season, there was no significant relationship between $\Delta Q$ or $\Delta Q_{\mathrm{w}}$ and $\Delta$ LML $\left(R^{2} \leq 0.05, F_{1,40} \leq 2.01, P \geq 0.164\right)$. However, when the analyses were conducted for discharge $\left(Q ; 1 \mathrm{~s}^{-1}\right)$ versus \% LML, a positive relationship was evident during the wet season $\left(R^{2}=0.19\right.$, $F_{1,81}=17.97, \quad P<0.001 ; \quad \arcsin \sqrt{\mathrm{LML}}=7.16 \times$ $\left.\log _{10} Q+33.67\right)$ that was not apparent during the dry season $\left(R^{2}=0.03, F_{1,53}=2.02, P=0.161\right)$. The effects of width-specific discharge $\left(Q_{\mathrm{w}}\right)$ on litter breakdown were likewise significant during the wet season only (wet: $R^{2}=0.17, \quad F_{1,81}=16.54, \quad P<0.001$; $\left.\arcsin \sqrt{\mathrm{LML}}=7.74 \times \log _{10} Q_{\mathrm{w}}+37.93\right)$.

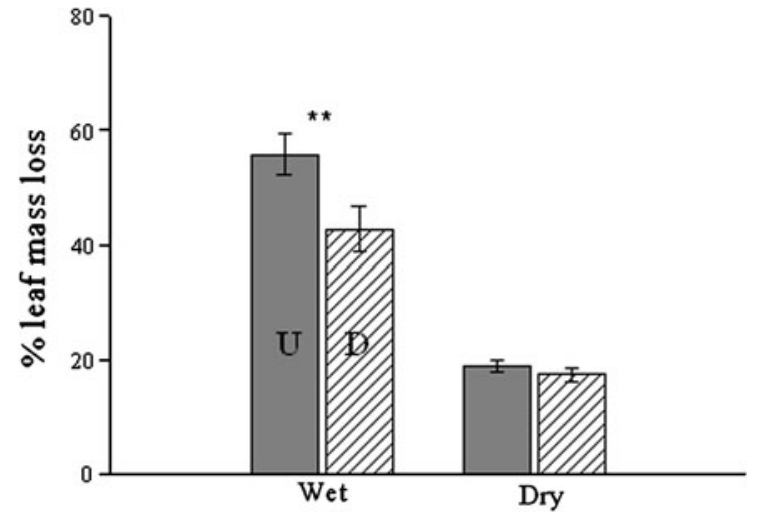

Fig. 2 Breakdown rates of Liquidambar formosana litter (mean \% leaf mass loss \pm SE) in up- $(U)$ and downstream (D) reaches across all the streams during each season. A significant between-reach difference $(* * P<0.01)$ was observed during the wet season

There were no inter-reach differences in abundance of total macroinvertebrates, B. hainanensis snails, or shredders during either season (Table 2). Total taxon richness (TTrich) was reduced in downstream reaches during both seasons, but the effect was greater during the dry season; diversity $\left(\exp H^{\prime}\right)$ declined downstream during the dry season only. Chironominae were more abundant downstream, especially during the dry season (Table 2). Hierarchical partitioning revealed that discharge was the best predictor of wet-season breakdown rates, and accounted for $61 \%$ of the total explained variation in this dependent variable (Fig. 3). None of the other variables were influential, although the largest contribution (11\% of explained variation) was made by TTrich. During the dry season, shredder abundance

Table 1 Results of repeated-measures ANOVAs for comparison of breakdown rates of Liquidambar formosana litter in up- and downstream reaches during the wet and dry seasons

\begin{tabular}{|c|c|c|c|c|c|c|c|}
\hline \multicolumn{4}{|l|}{ Three-way ANOVA } & \multicolumn{4}{|l|}{ Two-way ANOVA } \\
\hline & $F$ & df & $P$ & & $F$ & $\mathrm{df}$ & $P$ \\
\hline & & & & Wet & & & \\
\hline Reach & 13.477 & 1,8 & 0.006 & Reach & 14.812 & 1,8 & 0.005 \\
\hline Season & 112.282 & 1,8 & $<0.001$ & Stream & 3.140 & 8,64 & 0.005 \\
\hline Stream & 2.926 & 8,100 & 0.006 & Reach $\times$ stream & 0.517 & 8,64 & 0.839 \\
\hline Reach $\times$ season & 12.852 & 1,8 & 0.007 & Dry & & & \\
\hline Reach $\times$ stream & 0.485 & 8,100 & 0.864 & Reach & 2.237 & 1,8 & 0.173 \\
\hline Season $\times$ stream & 1.315 & 8,100 & 0.245 & Stream & 5.882 & 8,36 & $<0.001$ \\
\hline Reach $\times$ season $\times$ stream & 0.274 & 8,100 & 0.973 & Reach $\times$ stream & 1.520 & 8,36 & 0.185 \\
\hline
\end{tabular}


Table 2 A summary of benthic macroinvertebrate assemblage attributes (mean, and range in parentheses) in up- and downstream reaches across the 10 streams during the wet and dry seasons

\begin{tabular}{|c|c|c|c|c|}
\hline & \multicolumn{2}{|l|}{ Wet season } & \multicolumn{2}{|l|}{ Dry season } \\
\hline & Upstream & Downstream & Upstream & Downstream \\
\hline TTrich & $25.4(19.7-33.2)$ & $22.4(16.0-28.2)^{* *}$ & $30.4(24.0-35.3)$ & $24.8(14.7-34.0)^{* *}$ \\
\hline $\exp H^{\prime}$ & $39.7(22.3-65.1)$ & $34.9(15.4-63.1)$ & $52.4(26.3-82.0)$ & $31.4(7.8-61.9)^{* *}$ \\
\hline Abun & $246.7(114.8-547.5)$ & $229.0(123.6-456.7)$ & $225.7(104.0-382.3)$ & 331.8 (111.3-918.0) \\
\hline Chir & $21.1(4.8-52.6)$ & $36.6(3.8-105.6)^{* *}$ & 33.5 (15.7-93.0) & $60.7(12.7-146.3) * *$ \\
\hline Shre & $10.8(0-47.3)$ & $6.9(0-33.2)$ & $11.4(0-63.0)$ & $9.7(0-72.3)$ \\
\hline Brot & $10.0(0-46.7)$ & $6.2(0-33.2)$ & $10.3(0-62.7)$ & $8.7(0-71.3)$ \\
\hline
\end{tabular}

TTrich total taxon richness, exp $H^{\prime}$ diversity, Abun total macroinvertebrate abundance, Chir abundance of Chironominae, Shre shredder abundance, Brot abundance of Brotia hainanensis. Significant inter-reach differences are asterisked (ANOVA: $* * P<0.01)$

(37\%) and $\mathrm{PO}_{4}$ concentration (33\%) were the most important predictors, and the abundance of Chironominae was also influential (16\%) (Fig. 3). When shredders were substituted by B. hainanensis snails, similar results were obtained for both seasons, with snails and $\mathrm{PO}_{4}$ each contributing 34\% and Chironominae $14 \%$ of the total explained variation in dryseason breakdown rate.

\section{Discussion}

Liquidambar formosana litter generally decayed rapidly, in accordance with previous studies in Hong Kong streams (e.g. Li \& Dudgeon, 2009; Li et al., 2009). Faster breakdown during the wet season was attributable to increased discharge and warmer temperatures. Greater stream discharge tends to be associated with accelerated litter breakdown (Casas et al., 2000; Paul et al., 2006), because flow enhances physical abrasion and fragmentation of leaves (Webster \& Benfield, 1986; Lepori et al., 2005). Temperature stimulates the activity of aquatic fungi (hyphomycetes), which are the major contributors to litter breakdown in tropical streams (Padgett, 1976; Mathuriau \& Chauvet, 2002), and physical fragmentation of litter is enhanced if it has been softened by microbial activity (Bird \& Kaushik, 1992; Paul et al., 2006). In addition to seasonal variations in breakdown rate, inter-reach differences were evident and breakdown was slower in downstream reaches (mean \% LML: $54.9 \%$ upstream vs. $42.0 \%$ downstream) during the wet season. The importance of flow in determining between-reach differences in breakdown during the wet season in Hong Kong was confirmed by the positive relationship between discharge and breakdown rates, and this relationship was not seen in the dry season. We assume that this was due to a stronger physical processing of litter during the high flow period.

Litter breakdown rate are often positively correlated with nutrient loads (e.g. Suberkropp \& Chauvet, 1995; Rosemond et al., 2002). Total N was higher during the Hong Kong dry season, when $\mathrm{PO}_{4}$ also showed a non-significant increase, but their potential effects were overwhelmed by effects of seasonal variation in temperature and discharge. Nonetheless, $\mathrm{PO}_{4}$ concentration during the dry season (range = 2.6-6.4 $\mu \mathrm{g}^{-1}$ ) was one of the important predictors of breakdown rates, as has been reported in previous studies in Hong Kong (Li \& Dudgeon, 2009), presumably due to enhancement of microbial (fungal and bacteria) activity (Rosemond et al., 2002).

We expected that flow reduction would be associated with reduced litter breakdown in downstream reaches given flow-induced impairments in macroinvertebrate assemblages that we observed (Table 2: see also Niu \& Dudgeon, 2011). Muehlbauer et al. (2009) reported declines in macroinvertebrate diversity and fungal biomass on litter that were associated with slower breakdown rates under conditions of reduced flow, but retardation of breakdown related to flow reductions were only evident during the wet season, when stream flows were relatively high. The lack of any inter-reach difference during the dry season was similar to the findings obtained in inter-reach 


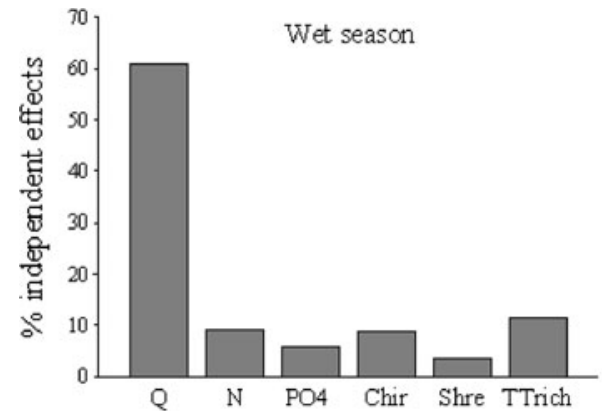

Fig. 3 Percentage contribution of each predictor variable (their independent effects) to the explained variation in breakdown rates of Liquidambar formosana litter during the wet and dry seasons as revealed by hierarchical partitioning

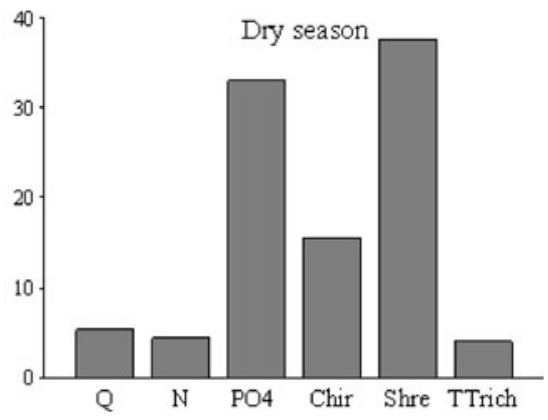

analyses. $Q$ discharge, $\mathrm{N}$ total inorganic nitrogen, $\mathrm{PO}_{4}$ total phosphate, Chir Chironominae abundance, Shre shredder abundance, Brot Brotia hainanensis abundance, TTrich total taxon richness of macroinvertebrates

observation that breakdown rates among streams during the dry season were influenced by shredder abundance (primarily B. hainanensis snails) in benthos samples and, to a lesser extent, the abundance of Chironominae (see above). We assumed that the composition and abundance of benthic macroinvertebrates would have been similar to those on litter, since they constitute the same taxa and there are virtually no species confined to litter (Dudgeon \& Wu, 1999; Li et al., 2009). Significantly, Li \& Dudgeon (2009) also found that breakdown rates of $L$. formosana were positively related to densities of benthic shredders during the dry season in eight Hong Kong streams (four shaded, four unshaded). The seasonal shift from determination of litter breakdown rates by flow volume during the high-discharge period (wet season) to a weaker dependence on flow under base-flow conditions (dry season) when biotic processes were more discernable is mirrored by studies of algal grazing in four unregulated Hong Kong streams where the influence of herbivorous fish detected during the dry season was overwhelmed by spate-induced disturbance during the wet season (Yang \& Dudgeon, 2010). It is conceivable that under high-flow conditions during the wet season, flow may fragment leaves so rapidly that it is the only determinant of breakdown rate. However, we did not measure microbial biomass or activity on litter during this study, and thus we cannot rule out potential effects of microorganisms during the wet season, nor can we estimate their contribution to breakdown during the dry season.

Apart from alterations in macroinvertebrate assemblages, flow reduction may also affect detritivore 
feeding rates upon leaf litter (Casas et al., 2000). Shredder feeding behaviour was beyond the scope of the present study, but shredders were generally scarce in all study reaches (mean $\%=3.9-6.3 \%$ of total abundance), as is typical of Hong Kong streams (e.g. Dudgeon \& Wu, 1999; Li \& Dudgeon, 2008, 2009), and did not differ significantly between reaches. Similarly, low abundance of shredders and a lack of response to flow reduction was reported from a regulated New Zealand forest stream (Death et al., 2009), although other changes in macroinvertebrate assemblages were apparent. Although the extent of inter-stream variation in the Hong Kong streams was large enough that shredder abundance could take account of a large proportion of explained variance $(>30 \%)$ of litter breakdown rate across streams, the between-reach variation in shredder abundance within each stream was relatively small. Furthermore, the abundance of the dominant shredder, the prosobranch snail B. hainanensis, was not related to discharge (Niu \& Dudgeon, 2011) perhaps because their ability to pump water through an internal gill chamber makes them less susceptible to flow reductions than other lotic species which depend upon the current to deliver oxygen to respiratory surface. A comparable situation occurred in a Maine stream where channelization and metal pollution reduced species richness and changed macroinvertebrate assemblage composition without a corresponding decline in litter breakdown rate, because the dominant tipulid (Diptera) shredder was tolerant of stress (Woodcock \& Huryn, 2005).

Seasonal patterns in the responses of litter breakdown to flow reduction, with greater between-reach differences in the wet season, were not consistent with the effects of flow reduction on macroinvertebrate assemblage structure. These were conspicuous during the dry season whereas only minor inter-reach differences were detected during the wet season (Niu \& Dudgeon, 2011). Evidently, this structural measure did not respond to anthropogenic disturbance in the same manner as the functional process of litter breakdown (but see also Bunn \& Davies, 2000; Sandin \& Solimini, 2009). Our findings accord with those of Casas et al. (2000) who reported that changes in shredder abundance and microbial biomass in a regulated Spanish streams did not result in significant changes in breakdown rate. Conversely, an increase in litter breakdown rates has been reported in the absence of changes in macroinvertebrate community structure in Swedish streams impacted by forest clear-cutting (McKie \& Malmqvist, 2009). Litter breakdown rate can affect the availability and temporal stability of allochthonous resources in the streams, as well as the downstream export of fine particulate organic material (FPOM) which can be consumed by collectors (e.g. Wallace et al., 1991). In this study, litter breakdown was slowed downstream of water extraction points during the wet season. The broader implications of these changes might include reduced downstream export of FPOM, with consequential effects for consumers downstream, but changes in organic matter dynamics were probably rather minor as frequent spates during the wet season would likely flush out even those reaches subject to flow extraction and thus prevent the substantial accumulation of litter at such sites. However, the litter exported from affected reaches under such circumstances would likely comprise larger leaf particles, rather than FPOM. The consequences for consumers further downstream would depend on the degree to which flow reduction affected litter breakdown rates, and our results indicate that LML was around $25 \%$ slower in reaches experiencing flow reduction during the wet season. Nonetheless, leaves in these reaches lost an average of $42 \%$ of their initial mass over a 28-day period, indicating that organic matter processing and litter fragmentation continued to take place, albeit at a reduced rate, which suggests that the potential effects on downstream export of FPOM may have been fairly minor.

Our results show that flow plays an important direct role in litter breakdown during high-flow periods, but is overwhelmed by biological processes during the low-flow conditions (Ferreira et al., 2006). Although litter breakdown rates appear to offer a promising functional indicator of the impacts of water extraction during in the wet season in Hong Kong, our wet-season data merely reflected the physical effects of flow rather than underlying biological processes, and the lack of a response to flow reductions during the dry season, when conditions are likely to be more critical for the biota, was notable. We conclude that this functional parameter provides complimentary information to the measurements of assemblage structure, but its potential for direct use in quantitative hydro-ecological models intended to establish e-flow allocations may be limited. 
Acknowledgments The work described in this article was partially supported by a grant from the Research Grants Council of Hong Kong Special Administrative Region, China (Project No. [HKU] 7509/06M), and by a postgraduate studentship awarded to Sophia Q. Niu during her M.Phil. studies at the University of Hong Kong. We thank Dr Nick Bond, Aggie O.Y. Li, Dr Brendan McKie, and an anonymous reviewer for their constructive comments on the manuscript. Our thanks extend to Eric Westhus and Dr Gerardo Camilo, for their advice on statistical analyses. Special thanks go to Lily C.Y. $\mathrm{Ng}$ for her technical support.

Open Access This article is distributed under the terms of the Creative Commons Attribution Noncommercial License which permits any noncommercial use, distribution, and reproduction in any medium, provided the original author(s) and source are credited.

\section{References}

APHA, 1995. Standard Methods for the Examination of Water and Wastewater, 19th ed. American Public Health Association, New York.

Arthington, A. H., R. J. Naiman, M. E. McClain \& C. Nilsson, 2010. Preserving the biodiversity and ecological services of rivers: new challenges and research opportunities. Freshwater Biology 55: 1-16.

Bird, G. A. \& N. K. Kaushik, 1992. Invertebrate colonization and processing of maple leaf litter in a forested and an agricultural reach of a stream. Hydrobiologia 234: 65-77.

Bunn, S. E. \& A. H. Arthington, 2002. Basic principles and ecological consequences of altered flow regimes for aquatic biodiversity. Environmental Management 30: 492-507.

Bunn, S. E. \& P. M. Davies, 2000. Biological processes in running waters and their implications for the assessment of ecological integrity. Hydrobiologia 422(423): 61-70.

Casas, J. J., C. Zamora-Muñoz, F. Archila \& J. Alba-Tercedor, 2000. The effect of a headwater dam on the use of leaf bags by invertebrate communities. Regulated Rivers: Research \& Management 16: 577-591.

Chevan, A. \& M. Sutherland, 1991. Hierarchical partitioning. The American Statistician 45: 90-96.

Death, R. G., Z. S. Dewson \& A. B. W. James, 2009. Is structure or function a better measure of the effects of water abstraction on ecosystem integrity? Freshwater Biology 54: 2037-2050.

Dewson, Z. S., A. B. W. James \& R. G. Death, 2007. A review of the consequences of decreased flow for instream habitat and macroinvertebrates. Journal of the North American Benthological Society 26: 401-415.

Dudgeon, D., 1992. The effects of water transfer on aquatic insects in a Hong Kong stream. Regulated Rivers: Research \& Management 7: 369-377.

Dudgeon, D., 1996. Anthropogenic influences on Hong Kong streams. GeoJournal 40: 53-61.

Dudgeon, D. \& R. T. Corlett, 2004. The Ecology and Biodiversity of Hong Kong. Friends of the Country Park and Joint Publishers, Hong Kong.
Dudgeon, D. \& K. K. Y. Wu, 1999. Leaf litter in a tropical stream: food or substrate for macroinvertebrates? Archiv für Hydrobiologie 146: 65-82.

Dudgeon, D., A. H. Arthington, M. O. Gessner, Z. I. Kawabata, D. J. Knowler, C. Lévěque, R. J. Naiman, A. H. PrieurRichard, D. Soto, M. L. J. Stiassny \& C. A. Sullivan, 2006. Freshwater biodiversity: importance, threats, status and conservation challenges. Biological Reviews 81: 163-182.

Ferreira, V., M. A. S. Graça, J. L. M. P. de Lima \& R. Gomes, 2006. Role of physical fragmentation and invertebrate activity in the breakdown rate of leaves. Archiv für Hydrobiologie 165: 493-513.

Gessner, M. O. \& E. Chauvet, 2002. A case for using litter breakdown to assess functional stream integrity. Ecological Applications 12: 498-510.

Gordon, N. D., T. A. McMahon, B. L. Finlayson, C. G. Gippel \& R. J. Nathan, 2004. Stream Hydrology: An Introduction for Ecologists, 2nd ed. Wiley, Chichester: 92-101.

Hagen, E. M., J. R. Webster \& E. F. Benfield, 2006. Are leaf breakdown rates a useful measure of stream integrity along an agricultural land use gradient? Journal of the North American Benthological Society 25: 330-343.

Hoover, T. M., J. S. Richardson \& N. Yonemitsu, 2006. Flowsubstrate interactions create and mediate leaf litter resource patches in streams. Freshwater Biology 51: 435-447.

Lancaster, J. \& B. J. Downes, 2010. Linking the hydraulic world of individual organisms to ecological processes: putting ecology into ecohydraulics. River Research and Applications 26: 385-403.

Lepori, F., D. Palm \& B. Malmqvist, 2005. Effects of stream restoration on ecosystem functioning: detritus retentiveness and decomposition. Journal of Applied Ecology 42: 228-238.

Li, A. O. Y. \& D. Dudgeon, 2008. Food resources of shredders and other benthic macroinvertebrates in relation to shading conditions in tropical Hong Kong streams. Freshwater Biology 53: 2011-2025.

Li, A. O. Y. \& D. Dudgeon, 2009. Shredders: species richness, abundance, and role in litter breakdown in tropical Hong Kong streams. Journal of the North American Benthological Society 28: 167-180.

Li, A. O. Y., L. C. Y. Ng \& D. Dudgeon, 2009. Effects of leaf toughness and nitrogen content on litter breakdown and macroinvertebrates in a tropical stream. Aquatic Sciences 71: 80-93.

Mac Nally, R., 2000. Regression and model-building in conservation biology, biogeography and ecology: the distinction between-and reconciliation of-'predictive' and 'explanatory' models. Biodiversity and Conservation 9: 655-671.

Mathuriau, C. \& E. Chauvet, 2002. Breakdown of leaf litter in a Neotropical stream. Journal of the North American Benthological Society 21: 384-396.

McKie, B. G. \& B. Malmqvist, 2009. Assessing ecosystem functioning in streams affected by forest management: increased leaf decomposition occurs without changes to the composition of benthic assemblages. Freshwater Biology 54: 2086-2100.

Muehlbauer, J. D., C. J. LeRoy, J. M. Lovett, K. K. Flaccus, J. K. Vlieg \& J. C. Marks, 2009. Short-term responses of 
decomposers to flow restoration in Fossil Creek, Arizona, USA. Hydrobiologia 618: 35-45.

Niu, S. Q. \& D. Dudgeon, 2011. How much water does a stream need? An empirical study of environmental flow allocations in monsoonal Hong Kong. Freshwater Biology (in press).

Padgett, D. E., 1976. Leaf decomposition by fungi in a tropical rainforest stream. Biotropica 8: 166-178.

Paul, M. J., J. L. Meyer \& C. A. Couch, 2006. Leaf breakdown in streams differing in catchment land use. Freshwater Biology 51: 1684-1695.

Poff, N. L. \& J. K. H. Zimmerman, 2010. Ecological responses to altered flow regimes: a literature review to inform the science and management of environmental flows. Freshwater Biology 55: 194-205.

Poff, N. L., B. D. Richter, A. H. Arthington, S. E. Bunn, R. J. Naiman, E. Kendy, M. Acreman, C. Apse, B. P. Bledsoe, M. C. Freeman, J. Henriksen, R. B. Jacobson, J. G. Kennen, D. M. Merritt, J. H. O'Keeffe, J. D. Olden, K. Rogers, R. E. Tharme \& A. Warner, 2010. The ecological limits of hydrologic alteration (ELOHA): a new framework for developing regional environmental flow standards. Freshwater Biology 55: 147-170.

Richter, B. D., 2010. Re-thinking environmental flows: from allocations and reserves to sustainability boundaries. River Research and Applications 26: 1052-1063.

Rosemond, A. D., C. M. Pringle, A. Ramírez, M. J. Paul \& J. L. Meyer, 2002. Landscape variation in phosphorus concentration and effects on detritus-based tropical streams. Limnology and Oceanography 47: 278-289.
Sandin, L. \& A. G. Solimini, 2009. Freshwater ecosystem structure-function relationships: from theory to application. Freshwater Biology 54: 2017-2024.

Short, R. A. \& J. V. Ward, 1980. Leaf litter processing in a regulated Rocky Mountain stream. Canadian Journal of Fisheries and Aquatic Sciences 37: 123-127.

Suberkropp, K. \& E. Chauvet, 1995. Regulation of leaf breakdown by fungi in streams: influences of water chemistry. Ecology 76: 1433-1445.

Wallace, J. B., T. F. Cuffney, J. R. Webster, G. J. Lugthart, K. Chung \& B. S. Goldowitz, 1991. Export of fine organic particles from headwater streams: effects of season, extreme discharges, and invertebrate manipulation. Limnology and Oceanography 36: 670-682.

Webster, J. R. \& E. F. Benfield, 1986. Vascular plant breakdown in freshwater ecosystems. Annual Review of Ecology and Systematics 17: 567-594.

Woodcock, T. S. \& A. D. Huryn, 2005. Leaf litter processing and invertebrate assemblages along a pollution gradient in a Maine (USA) headwater stream. Environmental Pollution 134: 363-375.

Yang, G. Y. \& D. Dudgeon, 2010. Response of grazing impacts of an algivorous fish (Pseudogastromyzon myersi: Balitoridae) to seasonal disturbance in Hong Kong streams. Freshwater Biology 55: 411-423.

Zar, J. H., 1999. Biostatistical Analysis, 4th ed. Prentice Hall, Upper Saddle River. 